R. BARLOW Magnetic Hysteresis Properties of Internally Oxidised Ni-Si

P. J. GRUNDY Alloys 1005

\title{
LETTERS
}

S. S. HECKER Comparison of Residual Stress Effects on the Yielding and

A. R. COOPER Fracture of Metal and Glass Composites · 1011

S. G. PATIL Non-Basal Dislocations in GaS Crystals 1013

R. H.WILLIAMS

C. P. BUHSMER Sub-Micron Sectioning Technique for Diffusion

Experiments $\cdot \mathbf{1 0 1 5}$

B. A. UNVALA Growth of Epitaxial Silicon Layers by Ion Beam

K. PEARMAIN Sputtering 1016

\section{SHORT NOTICES}

$\cdot 1018$

\section{Erratum :}

REDFERN, EVANS and WRONSKI. J. Mater. Sci. 5 (1970) 784.

Fig. $4 \mathrm{~b}$ was incorrectly printed, the amended figure is shown here.

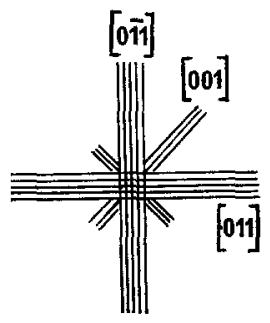

Technical articles of full page length, or over, appearing in Journal of Materials Science are indexed in British Technology Index, Current Contents, Science Citation Index (USA), and Engineering Index. Journal of Materials Science is also used by Chemical Abstracts, Metals Abstracts and Physics Abstracts.

\section{Subscription rates}

Subscription rate is: $£ 22.0 .0$ (US $\$ 56.00$ ) per annum; single copies $£ 2.10 .0$ (US $\$ 7.00$ ) Delivery charge is $12 \mathrm{~s}$ a volume surface mail, and $£ 7.10 .0$ a volume airmail.

Second class postage paid at New York, NY. US agents:

Air and Sea Freight lnc.

PO Box 1305, Long Island City, New York 11101, USA

(An annual volume consists of twelve issues.)

A few complete sets of Volume 1 (1966) (four issues), Volume 2 (1967) (six issues), Volume 3 (1968) (six issues) and Volume 4 (1969) (twelve issues) are available.

Enquiries for subscriptions and back numbers should be sent to:

Subscription Department,

Chapman and Hall, 11 New Fetter Lane, London EC4, UK 